\title{
Representações sociais entre estudantes brasileiros e portugueses em Universidades portuguesas
}

\author{
Aline Bazzarella Merçon ${ }^{1}$ \\ Maria Manuel Baptista ${ }^{2}$ \\ Kleber José dos Santos ${ }^{3}$
}

\begin{abstract}
Resumo
Tendo em conta que a diversidade trazida pelos imigrantes é um fator de desenvolvimento cultural, econômico e social e que reforça a importância da harmonia e do entendimento entre os povos, é pertinente perceber como se desenvolve a relação dos universitários brasileiros e portugueses em Portugal. O interesse deste estudo surgiu a partir da observação de práticas discursivas e obstáculos aparentemente trazidos por memórias coletivas do colonialismo identificadas na experiência desses imigrantes no país. Este artigo, de caráter interdisciplinar e ancorado na área dos Estudos Culturais, teve como objetivo principal analisar as representações sociais mútuas de estudantes brasileiros e portugueses das Universidades de Aveiro, Coimbra e Minho. Para além de fundamentos teóricos com base em uma revisão sistemática da literatura, o estudo empírico, de natureza predominantemente qualitativa, desenvolveu-se a partir da aplicação do grupo focal, submetido à Análise de Conteúdo. Esta metodologia possibilitou uma reflexão crítica e discussão sobre a questão das identidades, diversidades e interrelações culturais na era da globalização, ao mesmo tempo que também foram analisadas as potencialidades e dificuldades de natureza sociocultural que permeiam essas inter-relações no contexto lusófono.
\end{abstract}

Palavras-chave: Identidades; Interculturalidade; Representações Sociais; Estudantes brasileiros e portugueses.

\section{Introdução}

A imigração estudantil ainda é uma questão pouco explorada, pois é uma forma relativamente nova de imigração e vem trazendo à tona diversas discussões, tanto no que se refere ao processo de internacionalização das universidades, quanto em torno dos modos de inserção e adaptação dos estudantes estrangeiros no país de acolhimento. Na Europa, Portugal vem se destacando como um dos principais destinos dos imigrantes brasileiros. Esse fenômeno apresenta-se a partir de novas e variadas configurações, sendo impulsionado não somente por fatores relacionados com questões laborais ou melhores condições de vida, mas também por motivos de estudo.

Portanto, torna-se ainda necessário debater outras abordagens, como as representações sociais advindas da experiência da imigração estudantil, que, muitas vezes, são visitadas por

\footnotetext{
${ }^{1}$ Doutora em Estudos Culturais pelas Universidades de Aveiro e Minho - Portugal. Membro do grupo de pesquisa GECE (Grupo Gênero e Performance) da Universidade de Aveiro. Mestre em Ciências da Educação especialização em Formação Pessoal e Social pela Universidade de Aveiro. E-mail: alinebmercon@ hotmail.com

2 Professora Catedrática da Universidade de Aveiro. Doutora em Cultura pela Universidade de Aveiro. Mestre em Psicologia da Educação pela Universidade de Coimbra. E-mail: $\underline{\text { mbaptista@ua.pt }}$

${ }^{3}$ Doutor em Estudos Culturais com especialização em Hermenêuticas Culturais, Universidade de Aveiro (UA) e Minho (UMINHO). Mestre em Teatro/Artes Performativas pela Escola Superior de Teatro e Cinema de Lisboa (ESTC). E-mail: klaaskleberteatro@gmail.com
} 
questões pós-coloniais, identitárias e interculturais, sendo fundamental também abordar o tema da decolonização do pensamento.

Nessa perspectiva, a fundamentação teórica deste artigo apresenta-se com o propósito de dialogar e refletir sobre as práticas das representações sociais, identidades e alteridades, baseadas na compreensão em torno do exercício da linguagem, da significação, do conhecimento e do poder. Ainda neste âmbito, debruçou-se sobre as subjetividades que envolvem o tema proposto no debate contemporâneo.

Para tanto, o estudo empírico desenvolveu-se a partir da constituição de grupos focais, nos quais os resultados foram submetidos à Análise de Conteúdo. De acordo com Veiga \& Gondim (2001), o grupo focal, como estratégia metodológica qualitativa, é um recurso que envolve a partilha de opiniões e ideias, que favorece a obtenção de dados por meio do debate em grupo, para além de servir como um método de investigação social comprometido com a abordagem metacientífica compreensivista, ou seja, busca um maior entendimento acerca do processo de construção das percepções, atitudes e representações sociais de grupos humanos.

\subsection{Estudantes brasileiros em Portugal}

Para tratar do complexo cenário que envolve o deslocamento de estudantes brasileiros para Portugal é necessário refletir para além da dimensão formativa, a fim de compreender as dinâmicas que envolvem as vivências e desafios da imigração estudantil.

Neste sentido, primeiramente, cabe considerar sobre alguns aspectos que marcaram a evolução deste processo. Segundo Malheiros (2007), a imigração de brasileiros para Portugal é um fenômeno recente, que consolidou-se no decorrer das últimas três décadas. De acordo com o autor, o padrão migratório dos anos de 1990 caracterizou-se pelo baixo nível de qualificações desses indivíduos, fazendo com que esse fluxo migratório fosse considerado como "terceiromundista". Neste período, o movimento migratório de brasileiros para Portugal foi representado, sobretudo, pela entrada de pessoas com no máximo o ensino médio, as quais se estabeleceram, na maioria dos casos, como trabalhadores do setor secundário - do ramo da construção civil e do mercado dos serviços - e em atividades como a prostituição, podendo ter gerado também menores expectativas no mercado de trabalho e maiores dificuldades de integração.

Conforme esclarecem Malheiros e Baganha (2001), a recessão econômica no Brasil foi uma das razões da intensificação da imigração de brasileiros para Portugal, destacando-se como um processo de proletarização dos fluxos, marcado pela feminilização e etnicização, o que fez que a maioria das imigrantes brasileiras se inserissem em trabalhos com baixa qualificação, 
muitas vezes aquém de suas habilitações. Entre as ocupações dessas mulheres, a ligação com o mercado do sexo chamava atenção, resultando em associações atribuídas à esta "profissão", sendo criadas e reforçadas representações da "mulher brasileira", relacionadas com a prostituição e com uma imagem negativa, fortalecendo-se rótulos ou estigmas que ainda hoje não estão esgotados.

A este respeito, destacamos a influência dos discursos, narrativas e imagens midiáticas do Brasil e de seus nacionais, os quais, com efeito, intervieram de forma negativa na percepção portuguesa e internacional acerca dos brasileiros. De acordo com Lisboa (2010), desde meados do século $\mathrm{XX}$, o desenvolvimento dos meios de comunicação e das indústrias culturais dinamizaram a produção de conhecimento sobre o Brasil em Portugal, instalando-se um conjunto de imagens no coletivo português que redimensionaram as representações e estereótipos sobre os imigrantes brasileiros. Dada a expressividade numérica, a questão da imigração brasileira em Portugal foi amplamente abordada pelos meios de comunicação, sendo muitas vezes associada à temáticas negativas relacionadas à questão da ilegalidade, criminalidade e prostituição, que acabaram por contribuir para a consolidação de valores e imagens consubstanciadas na relação dicotômica "Nós/Outros".

Em contrapartida, as características desses imigrantes têm-se modificado ao longo dos últimos anos. A partir de 2010 a imigração de brasileiros para Portugal começou a ser representada por novos padrões, encontrando-se em uma outra fase. A atual onda migratória revela que os novos brasileiros não vão em busca apenas de uma melhor vida financeira, mas também à procura de um nível mais elevado de qualificações. Neste momento, estes indivíduos estão se estabelecendo como estudantes/qualificados — com formação de nível superior — proporcionando uma mudança gradual no perfil do imigrante brasileiro em Portugal (ALMEIDA, 2016).

Segundo complementam Zamberlan et al. (2009), ao observarmos os atuais fluxos migratórios do Brasil para Portugal, constatamos o surgimento de uma nova "vaga", que vem se estabelecendo e transformando os perfis destes imigrantes, sobretudo no que se refere ao seu estatuto socioeconômico e nível de qualificações. Se anteriormente o perfil dos imigrantes brasileiros estava situado em um estrato mais baixo e funcionava como um projeto de permanência no destino - que implicava trabalhar por um tempo com a finalidade de acumular bens para o seu retorno - hoje, surge uma nova modalidade, que consiste nas migrações temporárias com fins de estudos. De acordo com Rocha-Trindade et al. (1995), essa situação ocorre quando estudantes, geralmente de nível superior, visam obter em países estrangeiros determinadas qualificações, em cursos de longa duração. A autora afirma que "os movimentos 
migratórios, a que correspondem estadias a priori limitadas no tempo são considerados como migrações temporárias" (ROCHA-TRINDADE et al., p.36).

Nesta esfera, é necessário esclarecermos, de modo sucinto, o contexto que envolve a mobilidade estudantil internacional. No século XIX, a partir da emergência da ciência moderna, a formação de pessoas altamente qualificadas se tornou algo indispensável. Por uma série de razões socioeconômicas, a qualificação de pesquisadores do mundo não é homogênea. Muitos países, como o Brasil, têm buscado formas para qualificar os seus profissionais com a expertise instalada em países da Europa e América do Norte. Haja vista que oferecer condições necessárias para a qualificação dos seus pesquisadores, tanto em quantidade quanto em qualidade, é proporcionar a capacitação autônoma para o desenvolvimento tecnológico e científico de um país (VELHO, 2001).

É importante ressaltarmos que a internacionalização da educação deve ser compreendida como um fenômeno novo, estruturado na contemporaneidade, e que em função da globalização e das estratégias de internacionalização do ensino superior, não deve ser entendida apenas como um deslocamento de pessoas, mas como uma ligação entre países que implica um processo de relações entre culturas, funcionando como um recurso para desenvolver a qualidade do ensino e da pesquisa (CASTRO \& NETO, 2012).

Nos últimos anos o Brasil, considerado um país de desenvolvimento tardio, vem tentando superar as dificuldades marcadas no campo da educação. A saber, desde a época colonial as elites brasileiras miravam as Universidades de Coimbra e Lisboa em busca de uma educação superior. Apenas em 1920, timidamente, foi criada no Rio de Janeiro a denominada Universidade do Brasil. Este atraso, à luz das experiências dos países centrais, gerou graves consequências para o desenvolvimento da educação superior brasileira, refletindo, principalmente, em sua internacionalização, onde se percebe uma grande desigualdade no que diz respeito à estrutura física, aos recursos financeiros, ao prestígio dos atores envolvidos e à consolidação e capacidade de internacionalização (LIMA \& CONTEL, 2011).

Nos últimos anos, mais ainda com algumas limitações, o Brasil tem se esforçado para construir redes de universidades, programas de bolsas para o exterior, mobilidade docente e estudantil entre diferentes países, com o propósito de minimizar essas desigualdades, bem como para proporcionar aperfeiçoamentos pessoais e profissionais. Contudo, neste panorama, Portugal se tornou um dos principais países de acolhimento de estudantes brasileiros.

$\mathrm{Na}$ atualidade o ambiente universitário é visto como um espaço sociocultural em que as diversas presenças se encontram. Neste sentido, ressaltamos a importância em compreender os aspectos culturais, identitários e relacionais que envolvem a comunicação e as experiências 
pessoais destes estudantes. Conhecer a opinião e olhares de quem vive e sente em um país estrangeiro, apesar das proximidades linguísticas e culturais entre brasileiros e portugueses, facilita o entendimento acerca das identidades, das representações sociais recíprocas, bem como das diversidades lusófonas.

\subsection{Representações e identidades na prática do cotidiano}

Para compreender a relação entre o conceito de representações e identidades, principiamos por perceber a associação entre o significado das representações, da cultura e da linguagem. Segundo Santi e Santi (2008), a linguagem produz sentido, ou seja, as significações só podem ser partilhadas por meio do funcionamento comum da linguagem. O modo como percebemos, pensamos e representamos objetos, sujeitos ou fatos, estrutura e regulamenta as práticas sociais do cotidiano, logo, as linguagens funcionam como sistemas de representação. Deste modo, ao entender a cultura, com ênfase no significado e no desenvolvimento do senso comum, é possível compreender o exercício das representações.

O conceito de representações variam em diferentes níveis, como: representações de si mesmo, intergrupos, sociais e coletivas. Esses diferentes tipos de representações permitem abordar e articular a questão da identidade com relação às posições que os sujeitos ocupam na sociedade e em função das crenças partilhadas em um ambiente social, pois o conjunto de conhecimentos elaborados e cristalizados pelos indivíduos sobre si mesmos, outrem e outros grupos designam as representações identitárias (DESCHAMPS \& MOLINER, 2009). Com efeito, é possível compreender que a partilha de experiências e visões de mundo com outros na sociedade possibilita a construção de representações sociais, já que estas produzem conhecimentos e crenças que exercem papel fundamental e atribuem ao sentimento de identidade seu caráter contínuo.

Nesta vertente, Deschamps \& Moliner (2009) classificam três grandes categorias das estruturas do "si-mesmo": as estruturas do si-mesmo material, do si-mesmo pessoal e do simesmo social. Os autores reiteram que as ações, os processos comunicacionais e a influência social geram conhecimentos de si, sobre os outros e sobre os grupos. Consequentemente é possível reconhecer que o sujeito não é o único ator a compor a sua própria história ou autodeterminar sua construção identitária.

Pesavento (2003) destaca que as representações sociais também são "portadoras do simbólico, ou seja, revelam mais do que aquilo que mostram ou enunciam, carregam sentidos ocultos, que, construídos social e historicamente, se internalizam no inconsciente coletivo e se apresentam como naturais, dispensando reflexão" (p. 41). Dessa maneira o conceito de 
representação social é organizado a partir de modelos socioculturais resultantes de um processo de simbolização e de interpretação, que contribuem para a construção das identidades sociais.

Neste domínio, é possível constatar que as representações sociais também funcionam como um sistema de significação intimamente ligado às relações de poder, nas quais suas dimensões realçam os saberes específicos, tornando-os dominantes. É neste aspecto que as representações se conectam com a identidade e a diferença, pois "quem tem o poder de representar tem o poder de definir e determinar a identidade" (SILVA, 2000, p. 98). Logo, as identidades e as diferenças tendem a ser naturalizadas, essencializadas e cristalizadas.

Diante deste cenário, Maalouf (1999) defende a noção de “identidade compósita”. No seu entender, cada indivíduo possui uma identidade única e complexa, que é constituída por vários componentes, afiliações, multiplicidades e pertenças partilhadas, aproximando-se das mesmas concepções de Deschamps e Moliner (2009), que tratam sobre o fato do sujeito dispor, concomitantemente, de um conjunto de diferentes pertenças identitárias.

Contudo, Maalouf (1999) e Magano (2010) sustentam que essas pertenças passam por diversas progressões, as quais encontram-se em um processo de hierarquização, podendo ser mobilizadas segundo as condições experienciadas por cada indivíduo. Em outras palavras, podemos nos sentir pertencentes a várias e infinitas pertenças, mas com variações de importância, tendo em vista que não serão as mesmas combinações. É justamente isso que faz das pessoas distintas, evidenciando a riqueza de cada um e o valor pessoal faz dos indivíduos singulares e insubstituíveis.

Para Magano (2010), a capacidade do indivíduo de compreender a sua totalidade, está associada ao processo evolutivo e continuativo da identidade, possibilitando o desenvolvimento de estratégias identitárias que, por sua vez, pressupõem uma certa liberdade de ação de cada um, mediante os possíveis determinismos sociais.

Assim, entendemos que neste ambiente de multiplicidade de identificações partilhadas, a construção de diversos sentimentos de pertença e a diversidade dos aspectos de interação social permitem que um mesmo indivíduo ajuste e construa o seu discurso ou conduta, em função das situações mais adequadas (MARTINS, 2008). Em outras palavras, o sujeito age de acordo com um saber elaborado, que servirá às suas necessidades e aos interesses do grupo, permitindo comunicar e organizar os comportamentos de modo criativo e adaptativo (VALA, 2000).

Em outro ponto de vista, o estudo das identidades nos remete à discussão sobre o modelo de categorização dos grupos desenvolvido por Doise \& Deschamps (1980), que se baseia na dicotomia entre o individual e o coletivo, ou seja, em um processo de 
categorização/classificação entre "nós" e "eles". Conforme Deschamps \& Moliner (2009), a teoria da categorização, relativamente à percepção, apresenta-se por meio dos efeitos da acentuação das diferenças entre objetos, os quais, correspondem, ao mesmo tempo, a diferenciação e a similaridade entre objetos de uma mesma categoria, isto é, por sua função sistemática, a categorização procura tornar o mundo mais explicável, estruturado e ordenado.

O efeito da autocategorização e da assimilação traz uma consequência marcante na percepção dos grupos. Os indivíduos possuem a tendência em categorizar traços de personalidade ou atributos físicos comuns, isto é, classificar e definir por meio das características pessoais, físicas ou comportamentais um grupo de pessoas, o que resulta nos estereótipos. Logo, entende-se os estereótipos como um conjunto de crenças que permite caracterizar um grupo por meio de generalizações, descrevendo seus membros de forma rápida e consensual. Esse aspecto origina-se e pode ser explicado pelo processo de categorização social (DESCHAMPS \& MOLINER, 2009).

Para além do estereótipo ser um meio de categorizar e classificar as pessoas e os grupos através de traços ou características gerais, este também se define pelo compartilhamento de imagens mentais simplificadas e restritas a respeito de indivíduos ou acontecimentos. Estão sempre carregados de sentido, produzindo sentimentos de aceitação ou rejeição dos grupos, os quais constituem os preconceitos sociais.

Os preconceitos podem ser definidos como uma ideia preconcebida. São julgamentos prévios e atitudes pessoais emitidas sem fundamento, baseados em uma visão generalizada, falha e inflexível, contra um indivíduo ou a um grupo desvalorizado socialmente. A estereotipia gera a cristalização dos preconceitos que constituem um fenômeno social concebido no centro das relações desiguais entre os indivíduos, e se manifestam a partir de comportamentos excludentes (LIMA \& VALA, 2004).

Diante desse pressuposto, muitos autores, como também Amâncio (1996) e Bonomo e Souza (2007), defendem a ideia da importância do contato entre grupos e culturas distintas, haja vista que a interculturalidade pode beneficiar o desenvolvimento dos grupos como uma forma de reduzir o etnocentrismo, a xenofobia, a falta de informação e a hostilidade relativamente às minorias e às diferenças.

Neste sentido, é possível perceber que esse movimento possibilita pluralizar as práticas culturais, originando novos ambientes de pertença, pois a partir destes universos culturais plurais circulam e são formados, ambientes e práticas de vida, comportamentos e pensamentos, os quais, além de sedimentarem as identidades contemporâneas, poderão criar um espaço de representações interculturais (GIOIELLI, 2004). 


\subsection{Discursos pós-coloniais como abordagem crítica}

Com a finalidade de apresentar a visão de diferentes intelectuais sobre os discursos que abordam o pós-colonialismo, convém primeiramente registrar que, ainda hoje, não é possível afirmar a existência de uma efetiva teoria pós-colonial, pois os debates encontrados nada mais são do que diferentes construções, análises e percepções em torno deste campo de estudos. Como abordagem crítica aponta para diversos paradigmas epistemológicos e metodológicos, que tem como instrumento de análise as relações de poder e os efeitos homogeneizantes da globalização contemporânea.

Neste sentido, os estudos pós-coloniais, com abordagem multi-interdisciplinar, buscam refletir sobre questões de poder que se reproduzem nos diversos campos da vida social, dentro das esferas culturais, políticas, econômicas e epistêmicas. Logo, o pós-colonialismo necessita ser entendido mais como uma leitura crítica, uma "espécie de lente", que visa buscar o pensamento anticolonial e decolonial na contemporaneidade (BALLESTRIN, 2013).

Segundo Cantarino (2007), o pós-colonialismo se refere ao processo de decolonização que marcou, de formas diversas, os países colonizados e os países colonizadores. Esta relação é sustentada por traços e discursos de poder que se constituíram no eixo "dominador/dominado" ou na relação dicotômica "eu/outro". Portanto, "pensar nessa ambivalência posta pelo encontro colonial implica, assim, em deslocar uma série de noções como centro/periferia, nós/eles, dentro/fora, rompendo com essas oposições binárias para pensar as relações sociais de modo mais complexo, múltiplo e transversal" (CANTARINO, 2007, p. 1).

Os estudos pós-coloniais buscam desvelar estereótipos e prejuízos causados pela complexa teia de similaridades e diversidades coexistentes em uma sociedade. Além disso, têm a função de localizar historicamente as relações de poder e a subalternidade, apontando para a compreensão das realidades contemporâneas mundiais, que são múltiplas e entrecruzadas.

A estratégia dominante colonial, ao concentrar-se nas normas e seu cumprimento em benefício próprio, apropria-se da assimetria em seu diálogo para colocar em prática uma política de exploração e exclusão. Todavia, os dominados nem sempre são passivos na aceitação daquilo que lhes é imposto, pois, de sua íntima relação com a colonialidade, emerge uma força que rompe com a produção, circulação e recepção destes mecanismos marginalizadores (RIBEIRO \& PRAZERES, 2015).

Essa ideia de exclusão, no jogo das diferenças, cria uma noção imaginada de oposição, dissemelhança, desigualdade e representações em que os binarismos simplistas modernos 
tomam o espaço das instáveis, singulares e inovadoras différances ${ }^{4}$. É neste "entre lugar" das identidades simultâneas, onde se manifestam os fluxos ininterruptos constituídos pela différance ou diferença cultural, que o "desfetichizar" dos sujeitos subalternos torna-se possível, possibilitando a decolonização do pensamento (RIBEIRO \& PRAZERES, 2015).

Trazer à tona o debate acerca da différance e da distribuição desigual de poder exige pensar em universos contrários, pois somente a partir desta análise crítica é possível instituir resistências e reinvenções dos “entre lugares". Nesta lógica, segundo as autoras, "podemos, na leitura do mundo e de suas representações, criar e recriar diferenças plurais e incessantes, como em um devir infindável, um para sempre diferir" (RIBEIRO \& PRAZERES, 2015, p. 34).

De acordo com Bhabha (1998), essas reivindicações ou embates culturais de descentramento do sujeito, seja por meio de antagonismos ou por aproximações, são negociações complexas, visto que as representações das diferenças não devem ser interpretadas de maneira apressada. Para conferir autoridade aos hibridismos culturais, a articulação social da minoria e das diversidades devem abandonar os discursos dominantes. A luta pelo poder entre grupos diversos abre um espaço interrogativo: afinal, o que é uma comunidade? Seja ela branca, negra, latina, muçulmana, mulheres, colonizados, entre outros.

Nesse contexto, o direito de expressão a partir da periferia do poder depende do reconhecimento das identidades minoritárias, as quais, apesar das histórias comuns de privação e discriminação, podem concorrer e dividir-se entre si, não sendo sempre colaborativas e dialógicas.

Por estes motivos, os grupos desprivilegiados passam a reclamar o direito de suas identidades coletivas e da igualdade de tratamento das suas culturas no cenário internacional, reivindicando o reconhecimento de seus modos de ser e viver com tradições consideradas marginalizadas, ora no contexto da maioria, ora na sociedade dominada pelas forças globalizantes e eurocêntricas. Os rastros de um reconhecimento fracassado ou a aplicação uniformizadora das diferenças acabam por estabelecer o problema do nivelamento cultural às avessas, já que esta igualação também traz consequências aos grupos que se distinguem culturalmente uns dos outros, seja pela tradição, etnia, religião, formas de vida, etc (HABERMAS, 2002).

\footnotetext{
${ }^{4}$ Conceito defendido por Jacques Derrida (1991) que trata o termo diferença como différance, ou seja, como um lugar que evita remeter para o processo de diferir, não designando o exercício de cisão e divisão constituído na significação da palavra diferença. 
Neste sentido, tendo em vista o aparato teórico, apresentamos os dados produzidos no campo investigado, no qual desenvolvemos o percurso metodológico, a análise, interpretação e discussão dos dados.

\subsection{Análise de conteúdo e a prática do grupo focal}

Neste subitem descrevemos a metodologia utilizada neste estudo, fundamentada na análise de conteúdo. Técnica que permite organizar o discurso dos sujeitos da pesquisa, tornando possível delimitar um conjunto de categorias de significação, codificadas de acordo com os critérios de classificação. Estas categorias permitem a exploração, compreensão, associação e interpretação dos dados e das informações, a partir da sua própria estrutura (BARDIN, 1977; AMADO, 2014). Dessa forma para a análise de todo o material produzido, privilegiamos a dimensão interpretativa e os significados culturais, procedendo em quatro etapas metodológicas: 1) análise prévia; 2) exploração dos dados; 3) tratamento e interpretação dos dados e 4) discussão dos resultados das análises. Procedendo, em um primeiro momento, à leitura preliminar e exaustiva do corpus empírico.

O elemento determinante do grupo focal está no processo interativo desenvolvido entre os participantes e o entrevistador. A escolha desta técnica, como estratégia metodológica qualitativa, ocorreu devido ao fato deste recurso envolver a partilha de ideias e pontos de vista, favorecendo a obtenção de dados por meio do debate em grupo, em um curto espaço de tempo, podendo ser empregado para analisar determinados aspectos de um dado objeto, contribuindo para a obtenção de uma ampla variedade de dados, não facilmente alcançada por outros tipos de técnica de pesquisa (VEIGA \& GONDIM, 2001; AMADO, 2014). Esse debate em grupo teve como objetivo permitir o acesso a conteúdos das representações sociais entre brasileiros e portugueses, a fim de salientar a problemática que envolve as inter-relações mútuas e os obstáculos aparentemente trazidos por estereótipos identificados na vivência dos imigrantes brasileiros no país.

No que se refere aos procedimentos adotados, foram elaborados três roteiros de entrevista: um para o grupo dos alunos brasileiros, outro para o grupo dos alunos portugueses e por último para o grupo misto, que contou com a participação de brasileiros e portugueses, pertencentes às Universidades de Aveiro, Coimbra e Minho - Portugal.

Para tanto, utilizamos a técnica de amostragem por conveniência não probabilística (bola de neve). As sessões ${ }^{5}$ foram realizadas no período correspondente ao ano letivo de 2015 . A duração

\footnotetext{
${ }^{5}$ Estas realizaram-se a partir da autorização prévia das universidades portuguesas envolvidas e do termo de consentimento assinado pelos participantes. 
das sessões variou entre uma e duas horas e ocorreram dentro das instalações das Universidades mencionadas e em associações de estudantes.

A formação dos grupos se constituíram a partir da acessibilidade e colaboração voluntária dos estudantes, em cada uma das instituições envolvidas. Assim, o público-alvo foi composto por alunos brasileiros (público-alvo 1) e portugueses (público-alvo 2), de mestrado e doutorado, independente da área de estudos.

Ao todo, foram realizadas nove sessões de grupo focal: três em cada uma das instituições. Os grupos formados foram compostos por, no máximo, dez participantes por nacionalidade, totalizando sessenta e quatro sujeitos envolvidos na pesquisa.

A estratégia de unir estudantes de duas nacionalidades (brasileiros e portugueses) em uma das sessões foi considerada relevante, uma vez que, em termos de resultados, os sujeitos poderiam ter experiências diversas, em especial quando confrontados com a opinião dos outros estudantes de nacionalidade diferente.

\subsection{Procedimentos e análise dos dados}

Para apreender a diversidade no que diz respeito às experiências pessoais e pontos de vista distintos, buscamos envolver nesta pesquisa sujeitos de gêneros, idades, estados civis, habilitações e áreas de estudo diversos, regularmente matriculados e a frequentarem os programas de mestrado e doutorado das Universidades de Aveiro, Coimbra e Minho - Portugal.

O grupo que investigamos, bastante heterogêneo, sendo representado - de acordo com a técnica da análise de conteúdo, por (33) estudantes brasileiros e (31) portugueses, composto predominantemente por sujeitos com idades compreendidas entre os 30 e 40 anos, mulheres, solteiras, por doutorandas e por alunos da área das Ciências Humanas.

A partir da interação verbal entre todos os sujeitos integrantes das nove sessões de grupo focal realizadas, emergiram as representações recíprocas dos brasileiros e portugueses, bem como a auto representação do seu próprio grupo, a partir das quais despontaram as percepções sociais subjetivas socialmente partilhadas, constituindo assim uma base de dados para a nossa análise.

Conforme Amado (2014), procura-se, nesta auscultação, explicar e descrever a experiência, as atitudes, os sentimentos e as crenças dos participantes, como também perceber as reações geradas no interior do grupo em virtude dessas discussões.

Do material recolhido nas sessões de grupo focal, criamos uma listagem de palavras (175 palavras), acompanhadas das devidas frequências de ocorrência, associadas respectivamente ao grupo dos brasileiros e dos portugueses, o que deu origem a uma lista de 
vocábulos relativa às representações recíprocas e auto representações de ambos os grupos. Partindo deste rol, efetuamos uma análise sistemática de cada um dos vocábulos e da sua significação no contexto das discussões levadas a cabo no grupo focal. O vocabulário de conotação positiva, negativa e neutra constituiu-se de acordo com o sentido empregado pelos sujeitos da pesquisa no contexto das discussões do grupo focal, servindo como um meio para facilitar a análise.

Ao reunir estes vocábulos e características identificamos dimensões específicas, que foram construídas tendo em mente a conjuntura das interações do cotidiano e demandas sociais estabelecidas entre brasileiros e portugueses. Tais dimensões, que foram submetidas à técnica da análise de conteúdo, passam pelo campo profissional, social, histórico (em especial das relações coloniais entre Brasil e Portugal), emocional e de personalidade.

Esse método apoiou-se no modelo utilizado nos trabalhos das representações sociais de Vala (1981) e Valentim (2011), e dos estereótipos mútuos de Cabecinhas e Amâncio (2004).

Para tanto, o quadro a seguir sistematiza os resultados, primeiramente apresentando os vocábulos associados aos portugueses pelos brasileiros.

\section{Quadro 1}

Representação dos portugueses pelos sujeitos brasileiros

\begin{tabular}{|c|c|c|c|c|c|}
\hline Dimensão & $\begin{array}{l}\text { Características/ } \\
\text { vocábulos }\end{array}$ & $\begin{array}{c}\text { Sentido do } \\
\text { contexto } \\
\text { Positivo }\end{array}$ & $\begin{array}{c}\text { Sentido do } \\
\text { contexto } \\
\text { negativo }\end{array}$ & $\begin{array}{c}\mathbf{N}^{\mathbf{o}} \text { de } \\
\text { ocorrências }\end{array}$ & Total \\
\hline \multirow{3}{*}{ Profissional } & Comprometidos & $\mathrm{X}$ & & 5 & \multirow{3}{*}{15} \\
\hline & Individualistas & & $\mathrm{X}$ & 7 & \\
\hline & Reservados & $\mathrm{X}$ & & 3 & \\
\hline \multirow{4}{*}{ Social } & Frontais & $\mathrm{X}$ & & 5 & \multirow{4}{*}{27} \\
\hline & Grosseiros & & $\mathrm{X}$ & 8 & \\
\hline & Introvertidos & & $\mathrm{X}$ & 5 & \\
\hline & Preconceituosos & & $\mathrm{X}$ & 9 & \\
\hline Histórica & Conservadores & & $X$ & 5 & 5 \\
\hline \multirow{5}{*}{$\begin{array}{l}\text { Emocional e de } \\
\text { personalidade }\end{array}$} & Educados & $\mathrm{X}$ & & 7 & \multirow{5}{*}{35} \\
\hline & Antipáticos & & $\mathrm{X}$ & 3 & \\
\hline & Desconfiados & & $X$ & 6 & \\
\hline & Fechados & & $\mathrm{X}$ & 10 & \\
\hline & Sérios & & $\mathrm{X}$ & 9 & \\
\hline & \multicolumn{3}{|c|}{ Fonte: MERÇON (2020, p. 213). } & Total & 82 \\
\hline
\end{tabular}


Como podemos verificar no Quadro 1, as características atribuídas aos portugueses pelos sujeitos brasileiros encontram-se sobretudo relacionadas com a dimensão emocional e de personalidade, e apresentam um sentido negativo (fechados, sérios, desconfiados e antipáticos).

Ao observarmos a principal caracterização no domínio social (preconceituosos) e no domínio histórico (conservadores) percebemos uma inter-relação entre elas, cujos elementos remetem para questões históricas e culturais, dentre as quais se destacam a complexa relação colonial, trazendo à tona uma espécie de sentimento de "mágoa" referente ao ex-colonizador, a partir do qual se reproduzem representações sociais que reforçam o lado negativo dos portugueses.

Em seguida, expomos os resultados obtidos no que se refere aos vocábulos associados aos brasileiros pelos portugueses.

Quadro 2

Representação dos brasileiros pelos sujeitos portugueses

\begin{tabular}{|c|c|c|c|c|c|}
\hline Dimensão & $\begin{array}{l}\text { Características/ } \\
\text { vocábulos }\end{array}$ & $\begin{array}{c}\text { Sentido do } \\
\text { contexto } \\
\text { positivo } \\
\end{array}$ & $\begin{array}{c}\text { Sentido do } \\
\text { contexto } \\
\text { negativo } \\
\end{array}$ & $\begin{array}{c}\mathrm{N}^{\mathbf{o}} \text { de } \\
\text { ocorrências }\end{array}$ & Total \\
\hline Profissional & Descomprometidos & & $\mathrm{X}$ & 3 & 3 \\
\hline \multirow{6}{*}{ Social } & $\begin{array}{l}\text { Agrupados/ } \\
\text { associados }\end{array}$ & & $\mathrm{X}$ & 8 & \multirow{6}{*}{33} \\
\hline & Comunicativos & $\mathrm{X}$ & & 7 & \\
\hline & Acolhedores & $\mathrm{X}$ & & 5 & \\
\hline & Solícitos & $\mathrm{X}$ & & 5 & \\
\hline & Cordiais & $\mathrm{X}$ & & 4 & \\
\hline & Despreocupados & & $\mathrm{X}$ & 4 & \\
\hline Histórica & Ressentidos & & $\mathrm{X}$ & 4 & 4 \\
\hline \multirow{6}{*}{$\begin{array}{c}\text { Emocional e de } \\
\text { personalidade }\end{array}$} & Alegres & $\mathrm{X}$ & & 11 & \multirow{6}{*}{31} \\
\hline & Extrovertidos & $\mathrm{X}$ & & 6 & \\
\hline & Bem dispostos & $\mathrm{X}$ & & 5 & \\
\hline & Afáveis & $\mathrm{X}$ & & 3 & \\
\hline & Confiáveis & $\mathrm{X}$ & & 3 & \\
\hline & Exibidos & & $\mathrm{X}$ & 3 & \\
\hline & \multicolumn{3}{|c|}{ Fonte: MERÇON (2020, p. 214). } & Total & 71 \\
\hline
\end{tabular}

Como demonstra o Quadro 2, as características atribuídas aos brasileiros pelos sujeitos portugueses encontram-se sobretudo relacionadas com a dimensão social (comunicativos, acolhedores, solícitos e cordiais) e emocional e de personalidade (alegres, extrovertidos, bem dispostos, afáveis e confiáveis), todas de ordem positiva. Contudo, notamos que as associações negativas, como por exemplo: agrupados/associados, despreocupados, ressentidos, 
descomprometidos e exibidos foram emergindo à medida que os sujeitos portugueses eram provocados no decorrer dos debates. Este indicativo revela que as caracterizações negativas acerca dos brasileiros foram aos poucos externalizadas de forma implícita, destacando-se especialmente a característica de ordem social "agrupados/associados". Observamos também que, assim como no Quadro 1, algumas representações produzidas pelos portugueses sobre os brasileiros remetem para questões históricas, como, por exemplo, o atributo "ressentidos", dentre as quais se destaca a complexa relação colonial.

Nesta esfera, podemos chegar a uma conclusão de que, ao surgirem como representações antagônicas (que refletem a articulação entre identidade social e relações intergrupais), as percepções sociais de ambos os grupos mantém um padrão. Segundo explica Vala (1997):

[...] Estas representações desempenham um papel nas interações entre grupos. No entanto, muitos autores referem-se a um tipo particular de representações, $[\ldots]$ as que dizem respeito aos traços ou atributos personológicos que definem os membros de um grupo, ou seja, os estereótipos. Pouca atenção foi dada aos valores percebidos como distintivos de um grupo, às crenças que lhe servem de razão de ser ou, mais especificamente, às representações que os grupos criam sobre os objetos relevantes para o seu campo de ação e que são objeto de polémica ou cooperação social (VALA, 1997, p. 07).

Para uma abordagem teórica mais aprofundada, cabe esclarecermos que a representação social é mais abrangente do que o estereótipo, contudo este constitui uma parte importante da representação, permitindo a articulação entre ambos. A representação, com um objetivo prático e como uma modalidade de conhecimento socialmente elaborada e partilhada, leva os grupos e indivíduos a validar a realidade e as informações por meio de explicações sistematicamente enviesadas, sobre as quais também se produzem os estereótipos (BAPTISTA, 2004).

De acordo com a autora, trata-se de dois conceitos diferentes, que remetem para níveis de abordagem cujo grau de generalidade difere. Neste sentido, as representações sociais têm como função estruturar e orientar, tanto a comunicação quanto os comportamentos, enquanto os estereótipos servem para classificar os sujeitos pela sua pertença a determinados grupos.

Logo, os resultados apresentados revelam que a visão dos sujeitos da pesquisa sobre uns e outros fazem parte de uma crença compartilhada acerca de características e comportamentos, dos brasileiros e dos portugueses, considerados "usuais", os quais surgem como uma representação coletiva nos discursos destes indivíduos. Ou seja, se não compreendemos completamente os atos das outras pessoas, até que conheçamos os seus modos de ser e estar, para que as representações façam sentido, absorvemos os padrões e as versões correntes. Assim, neste caso, podemos inferir que a percepção social recíproca de ambos os grupos se constitui 
em um nível superficial e não em um nível profundo, no qual seja possível a individualização de cada sujeito.

Com efeito, as representações intergrupos são estruturadas a partir de categorizações sociais em torno de caracterizações e padrões partilhados pelo senso comum. As cognições simplificadoras relativas à categorização de pessoas geram comparações e diferenciações entre grupos, podendo exprimir formas de poder e conduzir à discriminação intergrupal (DESCHAMPS \& MOLINER, 2009; MOSCOVICI, 2009). Como complementa Paganotti (2007), a reprodução das representações e dos estereótipos acaba por originar generalizações, pré-concepções, modelos interpretativos preestabelecidos e, até mesmo, clichês. Essa praticidade e a divulgação superficial de informações podem, assim, transformar-se em preconceitos, reducionismos, exageros, etc.

Em seguida, apresentamos os resultados referente a auto representação dos sujeitos brasileiros participantes da pesquisa.

Quadro 3

Auto representação dos sujeitos brasileiros

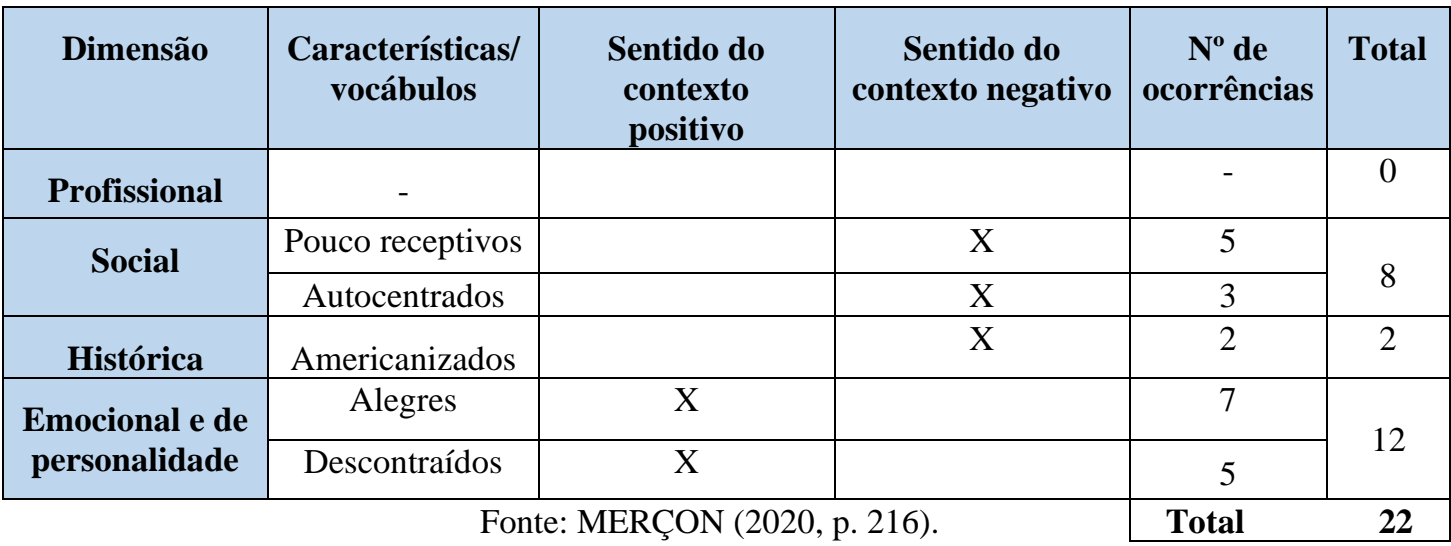

Como podemos observar no Quadro 3, os brasileiros autodefinem-se como alegres e descontraídos, ou seja com características positivas mais ligadas à dimensão emocional e de personalidade. Quanto às características de ordem social de pendor negativo, estes descrevemse como pouco receptivos e autocentrados, atributos que dizem respeito a uma tendência de preservação da própria cultura e resistência à cultura do "outro", indo de encontro à opinião dos sujeitos portugueses, quando apontam os brasileiros como "agrupados/associados" (Quadro 2). Esse aspecto parece-nos convocar a concepção de Maffesoli (1998) sobre os laços de uma 
comunidade emocional ${ }^{6}$, os quais servem para eleger os diferentes agrupamentos que constituem as sociedades contemporâneas, por meio de proximidades culturais, comunicacionais, nacionalismos, modismos, gênero, etc. "É neste quadro que as crenças comuns são elaboradas, ou, simplesmente, que se procura a companhia daqueles que pensam ou que sentem como nós" (MAFFESOLI, pp. 18-19).

No quadro seguinte, apresentamos os resultados referentes a auto representação dos sujeitos portugueses implicados na pesquisa.

\section{Quadro 4}

Auto representação dos sujeitos portugueses

\begin{tabular}{|c|c|c|c|c|c|c|}
\hline Dimensão & $\begin{array}{c}\text { Características/ } \\
\text { vocábulos }\end{array}$ & $\begin{array}{c}\text { Sentido do } \\
\text { contexto } \\
\text { positivo }\end{array}$ & $\begin{array}{c}\text { Sentido do } \\
\text { contexto } \\
\text { negativo }\end{array}$ & $\begin{array}{c}\text { Sentido do } \\
\text { contexto } \\
\text { neutro }\end{array}$ & $\begin{array}{c}\mathbf{N}^{\mathbf{0}} \text { de } \\
\text { ocorrências }\end{array}$ & Total \\
\hline \multirow{2}{*}{ Profissional } & Formais & & & $\mathrm{X}$ & 4 & 4 \\
\hline \multirow{2}{*}{ Social } & Passivos & & $\mathrm{X}$ & & 3 & 3 \\
\hline \multirow{2}{*}{ Histórica } & Colonialistas & & $\mathrm{X}$ & & 5 & \multirow{2}{*}{9} \\
\cline { 2 - 6 } Emocional e de \\
personalidade
\end{tabular}

De acordo com o Quadro 4, os sujeitos portugueses autodefinem-se tanto por meio de características de ordem emocional e de personalidade (fechados, resmungões e pessimistas) quanto histórica (patriarcais e colonialistas), ambas negativas. Como indicam os resultados, a auto representação dos sujeitos portugueses incide em questões histórico-culturais relacionadas com a colonização. Segundo Santos (2002), a partir da posição de colonizador/colonizado, que também marca o colonialismo subalterno português, solidificou-se a condição de país

\footnotetext{
${ }^{6}$ Conceito que trata do modo como as relações sociais são vividas, tendendo a prevalecer as emoções experienciadas em comum.

${ }^{7}$ Tendo em conta os debates nas diversas sessões de grupo focal, notamos que na perspectiva dos sujeitos portugueses as características "formais e fechados" são consideradas neutras, ao contrário da visão dos sujeitos brasileiros acerca dos portugueses.
} 
semiperiférico e da marginalidade lusitana, que permanece até à atualidade. Nesta perspectiva, o autor explica que a auto-imagem portuguesa oscila entre a representação de um dos detentores do maior e mais duradouro império colonial, memória romântica do herói constituída no século XVI, e a vivência em séculos posteriores do papel da marginalidade europeia.

Ao analisarmos o conjunto de resultados apresentados, é possível constatar que algumas características são comuns nas associações dos sujeitos brasileiros e portugueses, tanto nas representações atribuídas por cada grupo ao outro, como em suas auto representações. No caso dos portugueses, a característica "fechados" surge como representação comum a portugueses e brasileiros (Cf. Quadro 1 e Quadro 4). Já com relação aos brasileiros, a característica "alegres" é identificada como representação comum (Cf. Quadro 2 e Quadro 3).

Por último, construímos uma lista de palavras, que exprimem as representações dos sujeitos implicados na pesquisa, acerca do Brasil e de Portugal. Ao reunir estes vocábulos também identificamos dimensões específicas, que foram construídas considerando a visão do cotidiano dos brasileiros e portugueses. As dimensões utilizadas para esta análise referem-se ao campo simbólico (que remete ao âmbito dos significados abstratos e ao pensamento subjetivo) e concreto (que parte de uma significação relacionada à esfera do real e de uma ideia mais precisa).

Assim, demonstramos o quadro que apresenta, primeiramente, as representações dos sujeitos portugueses sobre o Brasil.

Quadro 5

Representação do Brasil pelos sujeitos portugueses

\begin{tabular}{|c|c|c|c|c|c|}
\hline Dimensão & Percepção & $\begin{array}{c}\text { Sentido do contexto } \\
\text { positivo }\end{array}$ & $\begin{array}{c}\text { Sentido do } \\
\text { contexto negativo }\end{array}$ & $\begin{array}{c}\mathrm{N}^{\circ} \mathrm{de} \\
\text { ocorrências }\end{array}$ & Total \\
\hline \multirow{4}{*}{ Simbólica } & $\begin{array}{l}\text { Desigualdade } \\
\text { social }\end{array}$ & & $\mathrm{X}$ & 6 & \multirow{4}{*}{19} \\
\hline & Corrupção & & $\mathrm{X}$ & 5 & \\
\hline & Pobreza & & $\mathrm{X}$ & 4 & \\
\hline & Violência & & $\mathrm{X}$ & 4 & \\
\hline \multirow{3}{*}{ Concreta } & Praias & $\mathrm{X}$ & & 8 & \multirow{3}{*}{15} \\
\hline & Calor & $\mathrm{X}$ & & 3 & \\
\hline & Novelas & $\mathrm{X}$ & & 4 & \\
\hline
\end{tabular}

Conforme observamos no Quadro 5, na visão generalizada dos sujeitos portugueses, o Brasil apresenta-se por meio de uma dimensão simbólica negativa (violência, corrupção, pobreza e desigualdade social), em detrimento de uma visão positiva mais concreta, baseada no 
clima, nas paisagens e nas novelas. Esse resultado significa que as visões e interpretações destes indivíduos sobre o Brasil são sobretudo do domínio imaginário, ou seja, suas percepções partem de representações partilhadas pela mídia e recepcionadas no cotidiano coletivo português.

Segundo os estudos de Pontes (2004) e Formiga (2015), no imaginário português contemporâneo a atuação da mídia brasileira e portuguesa, conjuntamente com as inter-relações estabelecidas entre a história e a cultura, constituem o eixo fundamental que norteia as interpretações simbolicamente partilhadas no cotidiano português sobre o Brasil.

Neste sentido, os resultados revelam que as imagens sobre o Brasil estão associadas ao cenário de insegurança generalizada, aos fatores socioeconômicos e à visão midiática excessivamente "tropicalizada".

A seguir apresentamos os resultados referentes às representações dos sujeitos brasileiros sobre Portugal.

\section{Quadro 6}

Representação de Portugal pelos sujeitos brasileiros

\begin{tabular}{|c|c|c|c|c|c|}
\hline Dimensão & Percepção & $\begin{array}{l}\text { Sentido do contexto } \\
\text { positivo }\end{array}$ & $\begin{array}{c}\text { Sentido do } \\
\text { contexto negativo }\end{array}$ & $\begin{array}{c}\mathrm{N}^{\circ} \mathrm{de} \\
\text { ocorrências }\end{array}$ & Total \\
\hline \multirow{2}{*}{ Simbólico } & $\begin{array}{l}\text { Desconhecimento } \\
\text { anterior sobre o país. }\end{array}$ & & $\mathrm{X}$ & 6 & \multirow{2}{*}{10} \\
\hline & $\begin{array}{l}\text { Estudantes brasileiros } \\
\text { ajudam a manter a } \\
\text { economia. }\end{array}$ & $\mathrm{X}$ & & 4 & \\
\hline \multirow{3}{*}{ Concreto } & Segurança & $\mathrm{X}$ & & 12 & \multirow{3}{*}{27} \\
\hline & Qualidade de vida & $\mathrm{X}$ & & 9 & \\
\hline & $\begin{array}{l}\text { Menos desenvolvido do } \\
\text { que outros países da } \\
\text { Europa. }\end{array}$ & & $\mathrm{X}$ & 6 & \\
\hline
\end{tabular}

De acordo com Quadro 6, para a maioria dos sujeitos brasileiros Portugal é representado por uma imagem concreta positiva (segurança, qualidade de vida). Observamos também que a visão negativa sobre Portugal está associada à condição de país semiperiférico, à crise econômica dos anos de 2015/2016, o que leva esses sujeitos a considerá-lo como um dos países menos desenvolvidos da Europa, e a um tipo de desconhecimento dos imigrantes brasileiros sobre o país antes de sua chegada.

Segundo Muniz (2009), a história do Brasil e de Portugal é marcada pelo distanciamento recíproco. De acordo com o autor, ainda hoje permanece a negação entre ambos os países, além de um desinteresse e o desconhecimento sócio-historiográfico, persistindo a incompreensão 
mútua entre Brasil e Portugal. Na sua opinião, a partir do estabelecimento da República (1889) o Brasil praticamente desconsiderou a História Contemporânea de Portugal, silenciando a sua herança com a antiga metrópole, renegando aspectos culturais e prevalecendo o esquecimento. Portugal, por sua vez, tem uma memória e imaginário imenso sobre as colônias, o que acarreta na reelaboração de uma extensa justificativa para o discurso do fundador e de seu imperialismo.

Logo, é neste processo complexo e paradoxal, nem sempre consciente, de sinuosidades, resistências e consequentes embates, que uma série de representações da identidade brasileira e portuguesa são constituídas (MACHADO, 2003).

\subsection{Representações sociais mútuas dos brasileiros e portugueses}

Ao analisar o conjunto de resultados que obtivemos acerca das representações sociais mútuas dos brasileiros e portugueses, destacam-se as questões identitárias frequentes construídas a partir do processo de negação do outro. Conforme salienta Silva (2000), as identidades e as diferenças emergem como conceitos quase que inseparáveis, pois, ao enunciar aquilo que não faz parte da nossa identidade ou com o que não nos identificamos, revela-se também implicitamente a produção de identidades invisibilizadas. Como produto das relações sociais, as identidades e as diferenças articulam-se e podem ser vistas a partir da lógica antagônica, exprimindo relações de poder, que conduzem à separação entre "nós e eles", onde o grupo privilegiado é sempre visto em primeiro plano e o segundo em uma posição de subalternidade, pois quem tem o poder de representar tem também o poder de estabelecer e definir a identidade e a diferença.

De modo geral, os resultados demonstram que as características atribuídas aos brasileiros pelos portugueses traduzem uma imagem tendencialmente mais positiva do que aquela que os brasileiros conferem aos portugueses. Neste sentido, os dados revelam a grande divergência entre os dois grupos sobre as representações mútuas. Do lado dos brasileiros, enquanto grupo imigrante, essa dissonância indica uma atmosfera de convivialidade, muitas vezes, desarmoniosa, ou seja, esta realidade acaba por contradizer a teoria da fraternidade entre os povos lusófonos.

No que diz respeito às representações mútuas, para além do atributo "fechados", caracterização maioritariamente referida pelos brasileiros sobre os portugueses (Cf. Quadro 1), e o atributo "alegres", dos portugueses sobre os brasileiros (Cf. Quadro 2), a característica "preconceituosos", com relação aos portugueses, também acaba por atravessar todo o discurso de ambos os grupos. No caso das auto representações, tanto os sujeitos portugueses quanto os 
brasileiros possuem uma opinião tendencialmente mais crítica e negativa do que positiva sobre si próprios (Cf. Quadros 3 e 4).

Ao confrontarmos os resultados obtidos, verificamos que tanto as caracterizações quanto as representações, mais negativas do que positivas sobre os portugueses, podem estar relacionadas com o fato de alguns dos estudantes brasileiros implicados na pesquisa já terem vivenciado situações de preconceito e/ou discriminação no meio acadêmico.

Com relação aos estudantes portugueses, verificamos, através da análise de conteúdo dos debates em grupo, que apesar destes reconhecerem que os brasileiros vivenciam situações negativas no ambiente acadêmico - como o preconceito, ainda assim os caracterizam de forma positiva, como também lhes atribuem uma representação mais positiva do que negativa (Cf. Quadro 2).

De acordo com Lima e Vala (2004), o preconceito sutil refere-se a uma nova expressão do preconceito, geralmente direcionado contra grupos externos e minorias culturais advindas das antigas ex-colônias. Esta forma de preconceito vem ganhando espaço na medida em que os efeitos da globalização intensificam os contatos interétnicos e os fluxos migratórios. Neste domínio, é possível observar que esta forma indireta de preconceito, efetiva-se por meio de crenças acerca de verdades e valores considerados adequados aos sujeitos em virtude de sua pertença a grupos específicos.

Neste contexto, observamos que os preconceitos e a discriminação contra grupos minoritários em sociedades igualitárias estão sendo facilitados por argumentos aparentemente livres de preconceito. Cabe destacar que este processo também envolve dimensões identitárias: as preocupações dos cidadãos nacionais estão ligadas à proteção da própria cultura, como os valores, os costumes, as tradições, os modos de vida, em suma, com o resguardo de uma identidade única. Esta ideia passa ainda pelo medo e desconfiança, que funcionam como um mecanismo justificador para a legitimação do apoio a políticas discriminatórias contra os imigrantes.

Para além disso, o interesse e conhecimento limitados sobre os indivíduos e grupos frente ao universo de informações, crenças e comportamentos que envolvem as relações interpessoais - favorece as percepções distorcidas. Assim, podemos afirmar que o ato de "rotular" é um processo que está articulado ao ato de representar. Essa dinâmica pode ser encontrada nos relacionamentos com os outros, quando lhes atribuímos determinados rótulos que permitem que certos tipos de comportamentos sejam antecipados. Esta tendência, embora comum, pode levar a erros de julgamento e contribuir para a disseminação de ideias, as quais fortalecem a consolidação de representações sociais e de preconceitos. 
Com efeito, Bauman (2009) salienta que, no atual mundo globalizado, o estrangeiro reflete o desconhecido passando a ser visto como "o perigoso e o desestruturador", cuja percepção favorece o individualismo e a exclusão, ao invés do diálogo significativo, onde a busca pelo reconhecimento recíproco pode criar pontos de compreensão entre a diversidade de culturas, histórias, necessidades e etc. Logo, os resultados apontam que as disputas identitárias também podem atravessar o processo migratório de estudantes.

\section{Considerações finais}

Como é possível observar, a Universidade é um lugar de encontro, de troca de culturas e saberes, ainda mais quando se trata do acolhimento de uma grande fatia de estudantes internacionais. As relações interculturais e a experiência da mobilidade são permeadas por um processo de transformação e por uma série de desafios, onde estes alunos necessitam enfrentar tensões emocionais, socioculturais e acadêmicas, que incluem perdas e ganhos (ANDRADE \& TEIXIERA, 2009; OLIVEIRA \& FREITAS, 2017).

Conforme os estudos de Oliveira \& Freitas (2017), os desafios advindos da presença de preconceito na trajetória acadêmica de alunos internacionais pode surgir como uma fonte potencial de tensão, que coloca estes indivíduos em uma posição de vulnerabilidade na sociedade anfitriã, bem como pode provocar um impacto negativo no processo de adaptação destes alunos. Logo, a evidência da reprodução de atitudes de preconceito no cotidiano português, em particular no meio universitário, indica dificuldades de pôr em prática uma educação e diálogo intercultural, que atua na contramão dos discursos que promovem formas de resistência às discriminações.

A este respeito, importa refletir acerca da importância de ações voltadas para a práxis intercultural a partir da "pedagogia das diferenças", pois em uma sociedade atravessada pelas diversidades é fundamental a existência de práticas pedagógicas que favoreçam a coesão social, de forma que o "outro cultural" deixe de ser um problema (SILVA, 2000; CANDAU, 2012).

Em complemento André (2012) elucida que o princípio da interculturalidade necessita superar a noção simplista de tolerância ou de uma visão benevolente de reciprocidade, pois o "outro" não é alguém que nobremente aceitamos. A experiência do reconhecimento mútuo busca um estado de paz, de aproximação, de troca de conhecimentos, do direito às diferenças, estabelecendo-se as interações no contexto de uma efetiva compreensão do "outro".

Portanto, os resultados sobre as representações recíprocas entre brasileiros e portugueses apontam para a necessidade da consciência da prática plural, na qual tais relações podem ser aperfeiçoadas a partir do entendimento sobre as diversidades no âmbito da 
Lusofonia, a fim de trazer benefícios para o processo de internacionalização da educação via língua portuguesa. Entender esta articulação seja relativamente ao gênero, a cultura, a etnia, ao pensamento, a formação, ao status social, entre outros, funciona como uma mediação entre a familiaridade e o estranhamento, como uma experiência do múltiplo sempre incompleto e aberto a novos aprendizados (ANDRÉ, 2012).

\section{Referências}

ALMEIDA, B. Exame.com. Disponível em: http://exame.abril.com.br/brasil/brasileirosbuscam-em-portugal-bem-estar-e-qualificacao/ Acesso em: 29 nov. 2016.

ANDRÉ, J. M. Multiculturalidade, identidades e mestiçagem: o diálogo intercultural nas ideias, na política, nas artes e na religião. Coimbra: Palimage, 2012.

AMADO, J. Manual de Investigação Qualitativa em Educação. 2 ed. Coimbra: Imprensa da Universidade de Coimbra, 2014.

AMÂNCIO, L. Identidade social e relações intergrupais. In: J. Vala; M. B. Monteiro (org.), Psicologia Social. Lisboa: Fundação Calouste Gulbenkian, 1996.

ANDRADE, A. M. J. d.; TEIXEIRA, M. A. P. Adaptação à universidade de estudantes internacionais: um estudo com alunos de um programa de convênio. Revista Brasileira de orientação profissional, n 10, 2009.

BALLESTRIN, L. América Latina e o giro decolonial. Revista Brasileira de Ciência Política, Brasília, n. 11, p. 89-117, 2013.

BAPTISTA, M. M. Estereotipia e Representação Social - uma abordagem psico-sociológica. In: Barker, A. (org.). A Persistência dos Estereótipos. Aveiro: Universidade de Aveiro, 2004, p. 103-116.

BARDIN, L. Análise de conteúdo. Lisboa: Edições 70, 1977.

BAUMAN, Z. Confiança e medo na cidade. Rio de Janeiro: Jorge Zahar, 2009.

BHABHA, H. K. O local da Cultura. Belo Horizonte: UFMG, 1998.

BONOMO, M.; SOUZA, L. D. Processos identitários e representações sociais em um cenário político conflituoso: quando os bezerros e os caranguejos se enfrentam. In: V JORNADA INTERNACIONAL E III CONFERENCIA BRASILEIRA SOBRE REPRESENTAÇÕES SOCIAIS, Brasília: 2007.

CABECINHAS, R.; AMÂNCIO, L. Estereótipos sociais e assimetria simbólica: três estudos com jovens angolanos e portugueses. In: VIII CONGRESSO LUSO-AFRO-BRASILEIRO DE CIÊNCIAS SOCIAIS, Coimbra: 2004. 
CANDAU, V. M. F. Diferenças Culturais, Interculturalidade e Educação em Direitos Humanos. Educ. Soc., v. 33, n 118, p. 235-250, 2012.

CANTARINO, C. Ficção Pós-Colonial retrata conflitos Contemporâneos. Ciência e Cultura, v. 59, n 2, 2007.

CASTRO, A. A.; NETO, A. C. O ensino superior: a mobilidade estudantil como estratégia de internacionalização na América Latina. Revista Lusófona de Educação, n 21, p. 69-96, 2012.

DERRIDA, J. Margens da filosofia. Campinas: Papirus, 1991.

DESCHAMPS, J. C.; MOLINER, P. A. Identidade em Psicologia Social: dos processos identitários às representações sociais. Petrópolis: Vozes, 2009.

DOISE, W.; DESCHAMPS, J. C.; MUGNY, G. Psicologia Social Experimental. Lisboa: Moraes Editores, 1980.

FORMIGA, S. C. X. As representações nas vossas cabeças: sobre o estereótipo midiático da mulher brasileira no imaginário português, 2015. Tese, Universidade do Porto, Porto, 2015.

GIOIELLI, R. L. P. Pistas para entender a identidade cultural no contexto da globalização. Novos Olhares, n 14, 2004.

GONDIM, S. M. G. Grupos Focais como técnica de investigação qualitativa: Desafios metodológicos. Paidéia, v. 12, n 24, p. 149-161, 2003.

HABERMAS, J. A Inclusão do Outro - Estudos de teoria política. São Paulo: Edições Loyola, 2002.

LIMA, M. C.; CONTEL, F. B. Internacionalização da Educação Superior: Nações ativas, nações passivas e a geopolítica do conhecimento. São Paulo: Alameda, 2011.

LIMA, M. E. O.; VALA, J. As novas formas de expressão do preconceito e do racismo. Estudos de Psicologia, v. 9, n 3, p. 401-411, 2004.

LISBOA, W. T. Fluxos transatlânticos e identidade: a imigração brasileira em Portugal e o imaginário português sobre o Brasil. In: XVII ENCONTRO NACIONAL DE ESTUDOS POPULACIONAIS - ABEP, Caxambú: 2010.

MAALOUF, A. As identidades assassinas. Miraflores: DIFEL, 1999.

MACHADO, I. J. D. R. Cárcere público: processos de exotização entre imigrantes brasileiros no Porto, 2003. Tese (Doutorado em Ciências Sociais) - Universidade Estadual de Campinas, São Paulo, 2003.

MAFFESOLI, M. Tempo das tribos: o declínio do individualismo nas sociedades de massa. Rio de Janeiro: Forense Universitária, 1998. 
MAGANO, O. "Tracejar vidas normais" - Estudo qualitativo sobre a integração social de indivíduos de origem cigana na sociedade portuguesa, 2010. Tese (Doutorado, em Sociologia Especialidade Relações Interculturais) - Universidade Aberta, Lisboa, 2010.

MALHEIROS, J.; BAGANHA, M. I. Imigração ilegal em Portugal: padrões emergentes em inícios do século XXI. Lisboa: Janus, 2001.

MALHEIROS, J. Imigração brasileira em Portugal. 1 ed. Lisboa: Alto Comissariado para a Imigração e Diálogo Intercultural (ACIDI), 2007.

MARTINS, A. S. A escola e a escolarização em Portugal - Representações dos Imigrantes da Europa do Leste. Lisboa: Alto Comissariado para imigração e diálogo intercultural, 2008.

MERÇON, A. B. Lusofonia e Identidade: Representações sociais recíprocas dos universitários brasileiros e portugueses, 2020. Tese (Doutorado em Estudos Culturais) - Universidade de Aveiro, Aveiro, 2020.

MOSCOVICI, S. Representações Sociais Investigações em psicologia social. 6 ed. Petrópolis: Vozes, 2009.

MUNIZ, T. S. As impossibilidades da "lusofonia" e as narrativas acerca do "outro e do "eu" entre Brasil e Portugal. Revista Brasileira de História \& Ciências Sociais, v. 1, n 2, 2009.

OLIVEIRA, A. L. D.; FREITAS, M. E. D. Relações interculturais na vida universitária: experiências de mobilidade internacional de docentes e discentes. Revista Brasileira de Educação, v. 22, n 70, 2017.

PAGANOTTI, I. Imagens e estereótipos do Brasil em reportagens de correspondentes internacionais. Revista de Comunicação, Linguagem e Mídias, 2007.

PESAVENTO, S. J. História \& História Cultural. 1. ed. Belo Horizonte: Autêntica, 2003. PONTES, L. Mulheres brasileiras na mídia portuguesa. Cadernos Pagu, n 23, p. 229-256, 2004.

RIBEIRO, M. A. ;PRAZERES, L. G. L. A produção da subalternidade sob a ótica Pós-colonial (e descolonial): algumas leituras. Temáticas, p. 25-52, 2015.

ROCHA-TRINDADE, M. B.; HORTA, A. P. B.; RIBEIRO, J. Sociologia das Migrações. Lisboa: Universidade Aberta, 1995.

SANTI, H. C.; SANTI, V. J. C. Stuart Hall e o trabalho das representações. Revista Anagrama - Revista Interdisciplinar da Graduação, ed 1, 2008.

SANTOS, B. D. S. Para uma sociologia das ausências e uma sociologia das emergências. Revista Crítica de Ciências Sociais, n 63, 2002.

SILVA, T. T. A produção social da identidade e da diferença. In: T. T. Silva (org.). Identidade e diferença: a perspectiva dos Estudos Culturais. Petrópolis: Vozes 2000, p. 73-102.

VALA, J. Grupos sociais e representação social da violência. Psicologia 2, n 4, p. 329-342, 1981. 
VALA, J. Representações sociais e percepções intergrupais. Análise Social, v. 140, p. 7-29, 1997.

VALA, J.; MONTEIRO, M. B. Psicologia Social. 4 ed. Lisboa: Serviço de Educação Fundação Calouste Gulbenkian, 2000.

VALENTIM, J. P. Representações sociais do luso-tropicalismo e olhares cruzados entre portugueses e africanos. Coimbra: Universidade de Coimbra, 2011.

VEIGA, L.; GONDIM, S. M. G. A utilização de métodos qualitativos na ciência política e no marketing político. Opinião Pública, n 2, p. 1-15, 2001.

VELHO, L. Formação de Doutores no País e no Exterior: Estratégias Alternativas ou Complementares? Dados, Rio de Janeiro, v. 44, n. 3, p. 607-631, 2001.

ZAMBERLAM, J. et al. Estudantes internacionais no processo globalizador e na internacionalização do ensino superior. Porto Alegre: Solidus, 2009. 


\title{
Representaciones sociales entre estudiantes brasileños y portugueses en universidades portuguesas
}

\begin{abstract}
Resumen
Teniendo en cuenta que la diversidad que aportan los inmigrantes es un factor de desarrollo cultural, económico y social y que refuerza la importancia de la armonía y el entendimiento entre los pueblos, es pertinente percibir cómo se desarrolla en Portugal la relación entre los universitarios brasileños y portugueses. El interés surgió de la observación de prácticas discursivas y obstáculos aparentemente traídos por memorias colectivas del colonialismo identificadas en la experiencia de estos inmigrantes en el país. Este artículo, de carácter interdisciplinario y anclado en el área de los Estudios Culturales, tenía como objetivo principal analizar las representaciones sociales mutuas de los estudiantes brasileños y portugueses de las Universidades de Aveiro, Coimbra y Minho. Además de los fundamentos teóricos basados en un examen sistemático de la literatura, el estudio empírico, de carácter predominantemente cualitativo, desarrollado a partir de la aplicación del grupo de discusión, se sometió al análisis de contenido. Esto permitió una reflexión crítica y un debate sobre la cuestión de las identidades, las diversidades y las interrelaciones culturales en la era de la globalización, al mismo tiempo, también se analizaron las potencialidades y dificultades de carácter sociocultural que impregnan estas interrelaciones en el contexto lusófono.
\end{abstract}

Palabras clave: Identidades; Interculturalidad; Representaciones sociales; Estudiantes brasileños y portugueses.

\section{Représentations sociales entre étudiants brésiliens et portugais dans les universités portugaises}

\begin{abstract}
Résumé
Sachant que la diversité apportée par les immigrés est un facteur de développement culturel, économique et social et qui renforce l'importance de l'harmonie et de la compréhension entre les peuples, il est pertinent de comprendre comment se développe la relation des étudiants universitaires brésiliens et portugais au Portugal. L'intérêt de cette étude est né de l'observation des pratiques discursives et des obstacles apparemment apportés par les mémoires collectives du colonialisme identifiées dans l'expérience de ces immigrés dans le pays. Cet article, à caractère interdisciplinaire et ancré dans le domaine des études culturelles, avait pour objectif principal d'analyser les représentations sociales mutuelles des étudiants brésiliens et portugais des universités d'Aveiro, Coimbra et Minho. Outre les fondements théoriques fondés sur une revue systématique de la littérature, l'étude empirique, à caractère essentiellement qualitatif, développée à partir de l'application du focus group, soumise à l'analyse de contenu. Cette méthodologie a permis une réflexion critique et une discussion sur la question des identités culturelles, des diversités et des interrelations à l'ère de la mondialisation, tout en analysant les potentialités et les difficultés de nature socioculturelle qui imprègnent ces interrelations dans le contexte lusophone.
\end{abstract}

Mots clés: Identités; Interculturalité; Représentations sociales; Étudiants brésiliens et portugais.

\section{Social representations between Brazilian and Portuguese students in Portuguese universities}

\begin{abstract}
Bearing in mind that the diversity brought by immigrants is a factor of cultural, economic and social development and that it reinforces the importance of harmony and understanding among people, it is relevant to realize how the relationship of Brazilian and Portuguese undergraduates develops. The interest of this subject arose due to the observations of discursive practices and obstacles apparently brought by collective memories of colonialism identified in the experience of these immigrants in the country. This article, with interdisciplinary character and anchored in the area of cultural studies, had as a main objective the analysis of mutual social representations of


Brazilian and Portuguese students from the Universities of Aveiro, Coimbra and Minho. In addition to theoretical foundations based on a systematic review of the literature, the empirical study, predominantly qualitative, developed from the application of focus group submitted to the content analysis. This methodology enabled a critical reflection and discussion about identities, diversities and cultural interrelations in the era of globalization, while also analysing the socio-cultural potentialities and difficulties that permeate the interrelations in the lusophone context.

Keywords: Identities; Interculturality; Social Representations; Brazilian and Portuguese students. 